\title{
Preoperative irradiation therapy and radical hysterectomy: prognostic value of tumor regression after initial irradiation of squamous cell carcinoma of the cervix
}

\author{
Departments of Gynecology and Epidemiology, Hospital A.C. Camargo, FAP - São Paulo, Brazil \\ Division of Epidemiology, Department of Oncology, McGill University - Montreal, Canada
}

\begin{abstract}
Objective: To investigate the role of tumor persistence in patients submitted to irradiation therapy and radical hysterectomy. Design: A retrospective analysis of prognostic factors. Location: Hospital A.C. Camargo, São Paulo, Brazil, a private non-profitmaking foundation and tertiary referral centre. Patients: A total of 629 cases of invasive squamous cell carcinoma of the cervix were studied. Criteria for inclusion in the study were: confirmed histological diagnosis of squamous cell carcinoma and no previous treatment (except for preoperative radiotherapy carried out at the Hospital A.C. Camargo itself). At the end of the follow-up period, 410 patients (65\%) had no evidence of disease and $219(34.8 \%)$ had died because of the tumor. Intervention: The patients were submitted to radical surgery and radiation therapy, separately or in combination between 1953 and 1982 . Main outcomes measures: Multivariate analysis of the different variables was performed according to the Cox regression method. Results: The variables of prognostic value were, in decreasing order of importance: the decade of patient admission $(p=0.0001)$, the modality of therapy employed $(p=0.0005)$, the presence of residual tumor in the surgical specimens $(p=0.0055)$ and the clinical stage of the disease $(p=0.0575)$. Conclusion: Radiation therapy controlled a considerable number of local tumors and pelvic lymph nodes but not all of them in every patient. There is a specific group of patients for whom radical surgery is necessary to achieve control of the disease.
\end{abstract}

UNITERMS: Squamous cell. Cervical cancer. Cervix uteri. Hysterectomy. Radiotherapy. Multivariate Analysis.

\section{INTRODUCTION}

I $\mathrm{n}$ the 1920's and over the next two decades, radiotherapy occupied a predominant position in the treatment of carcinoma of the cervix.(1) Towards the end of the 1940's, with the introduction of modern anesthesia, surgery began to reappear as an alternative method for stages I and II. This revival of surgery should

\section{Address for correspondence:}

Francisco Ricardo Gualda Coelho

Rua Décio de Almeida Filho, 421

Campinas/SP - Brasil - CEP 13084-710 probably be ascribed mainly to Meigs, ${ }^{(2)}$ who decided to combine lymphadenectomy according to Taussig's method with Wertheim's radical operation. ${ }^{(3,4)}$

The search for the optimum treatment of carcinoma of the cervix continues because of various unresolved controversies caused by the multifactorial nature of the problem. Many investigators agree that optimal patient survival can best be achieved by tailoring of treatment methods to the requirements of each patient. ${ }^{(5)}$

Patients with cervical cancer who fail to be cured by conventional therapy tend to fall into one of two categories, namely, those with persistent primary tumor or recurrence after treatment, and those with tumor which has spread to regional lymph nodes in the pelvis. ${ }^{(6)}$ Tumor persistence 
after initial brachytherapy has been considered to be an unfavorable prognostic factor. ${ }^{(7,8)}$

The present investigation was undertaken in order to investigate the role of irradiation therapy and radical hysterectomy performed over three decades at the same Institution.

\section{METHODS}

A retrospective study was conducted on 629 consecutive patients with primary squamous cell carcinoma of the cervix submitted to surgical treatment alone or in combination with pre-operative or postoperative radiotherapy in the Department of Gynecology, Hospital A.C. Camargo, Antonio Prudente Foundation, São Paulo, from 1953 to 1982.

Criteria for inclusion in the study were: confirmed histological diagnosis of squamous cell carcinoma of the cervix, no previous treatment (except for preoperative radiotherapy carried out at the Hospital A.C. Camargo itself), and radical curative surgery as the major treatment, alone or in combination with preoperative and/or complementary radiotherapy.

Patients who presented at least two of the following characteristics were excluded from the study: refusal to undergo surgery, advanced disease (local or at a distance), operated tumors and/or tumors treated with radiotherapy without radical hysterectomy, and contraindication of radical surgery (inoperability).

The numbers and percentages of patients studied over the three decades from 1953 to 1982 were as follows: 19531960, 221 cases (35.1\%); 1961-1970, 205 cases (32.5\%); 1971-1982, 203 cases (32.2\%). Patients' ages ranged from 18 to 72 years (mean 44.1; median 44.0). In terms of ethnic group, 446 patients were white (70.9\%), 22 oriental (3.4\%), 87 non-white $(13.8 \%)$, and 74 of unknown race $(11.7 \%)$

Clinical stage, determined according to the International Federation of Gynecology and Obstetrics, was as follows: 186 patients $(29.5 \%)$ were of stage I, 322 $(15 \%)$ of stage II, $107(17 \%)$ of stage III, and $14(2.2 \%)$ were of unknown stage. The clinical criterion was not modified as a function of the transoperative findings. Thus, patients with apparent preoperative extension of the tumor to the parametrium and considered to be stage III $b$ were included in the series, when operated.

Surgery was performed as the only treatment in 37 cases $(5.8 \%)$; preoperative brachytherapy followed by surgery was indicated in 228 cases (36.2\%); brachytherapy followed by external radiotherapy and surgery was performed in 262 cases (41.6\%); brachytherapy followed by surgery and later complemented with external radiotherapy was performed in 40 cases $(6.3 \%)$; surgery followed by brachytherapy was performed in 8 cases $(1.27 \%)$. Fifty-four patients (8.5\%) were submitted to other treatment combinations (miscellaneous group). This group included 13 patients (2\%) submitted to chemotherapy. The surgery performed in all 629 cases was radical hysterectomy by the Wertheim-Meigs technique. ${ }^{(2,3,4,9)}$

When indicated, radiotherapy for carcinoma of the cervix was performed as a combination of external megavoltage radiotherapy and intracavity radiotherapy. External irradiation was performed using a cobalt unit or a linear accelerator in an arrangement involving two or four pelvic fields depending on the dimensions of the patient and on the volume of irradiation. Up to 1972, pelvic irradiation was performed using cobalt units, and a $4 \mathrm{MeV}$ linear photon accelerator started to be used thereafter. ${ }^{(10)}$ Up until 1983, a total irradiation dose of 4,000 cGy divided into 20 fractions of $200 \mathrm{cGy}$ was used for radiotherapy.

The intracavity brachytherapy used here follows the Manchester school, with a definition of the dose at the socalled A and B points. The original applicators used in this technique (a uterine probe and colpostats) were preloaded with radium 226 sources and used in this manner until 1970. After 1970, cesium 137 was used in place of radium 226 and the after-loading system was routinely introduced. ${ }^{(10)}$ A dose of 4,000 cGy was delivered to the pelvis and was complemented with brachytherapy of 3,000-3,500 cGy when a uterine probe and vaginal colpostats were used. In cases of postoperative treatment, the same scheme of pelvic irradiation was used in combination with brachytherapy of the vaginal fundus using a pair of colpostats that released 4,000 cGy into the mucosa in a single insertion. ${ }^{(10)}$

Examination of the anatomopathological results for surgical specimens from patients submitted to surgery showed that no type of residual disease was detected in the cervix and/or locoregional lymph nodes of most patients (469 cases, $74.5 \%$ ).

The associations of the different variables available from the medical records of the 629 patients were analyzed on a microcomputer using specific software for databank management and statistical analysis.

The time (months) from the date of the beginning of treatment until death or until the latest follow-up information corresponded to the overall survival. Actuarial survival estimates were calculated by the technique of Kaplan and Meier. ${ }^{(11)}$ Survival distributions for the categories of the same variables were compared by the Mantel-Cox test. ${ }^{(12,13)}$ Exact $\mathrm{P}$ values were obtained by calculating the residual area using chi-square distribution. 
This analysis was performed using the microcomputer program KMSURV. ${ }^{(14)}$ After analysis of the association of each variable with survival, we investigated multifactorial models with the maximum prognostic value in terms of the joint survival of the patients studied using the Cox multivariate technique.

\section{RESULTS}

Overall patient survival ranged from less than 1 month to 368 months (median: 74.2 months). At the end of the follow-up period, 410 patients $(65 \%)$ had no evidence of disease and $219(34.8 \%)$ had died because of tumor recurrence or because of treatment complications. Patient follow-up was $100 \%$ up to the end of the study, i.e., no patient was lost to follow-up. In six cases, survival was considered to be zero because the patients died during the transoperative or immediate postoperative period. These patients were not included in the survival analysis.

The patients were divided into three decade groups in terms of year of admission, i.e., 1950's, 1960's and 1970's. Overall survival rates among the patients treated in the 1970 decade and the beginning of the 1980 decade were higher than those for the other decades (Figure 1).

When all the categories related to treatment were analyzed, the subgroup of patients submitted to surgery alone showed a significantly higher overall survival rate when compared to those women whose treatment involved combined radiotherapy during the preoperative or postoperative period. When a comparison was made between the groups for whom radiotherapy was indicated, there was no difference in survival between: patients submitted to preoperative brachytherapy, versus patients submitted to preoperative brachytherapy combined with external preoperative radiotherapy, versus patients submitted to postoperative brachytherapy. The difference was greater, with a consequent reduction in overall survival, in those patients assigned to the miscellaneous group (Figure 2).

Overall survival of stage I patients was significantly higher than that of stage II and III patients and this difference continued to be present when the patients were analyzed in terms of five- and 10-year survival.

There was no difference in survival between stage II and stage III patients. In cases in which staging was considered to be unknown because of the lack of appropriate information, survival was similar to that of stage II and III patients (Figure 3).

Overall survival rates for patients who were alive after five years decreased significantly with the number of lymph nodes involved. The patients with no lymph nodes involved presented clearly better survival than the patients with a lymph node involved. This difference was maintained in a progressive manner when the patients with two to three lymph nodes involved were analyzed. Paradoxically, the comparison with the subgroup of patients with four to nine lymph nodes involved did not show such a great difference although when this variable was analyzed grouping the patients into a single category, it was significantly different among the four groups studied (Figure 4).

A significant five-year survival was observed when no residual tumor was detected in the anatomopathological examination of the surgical specimen. Conversely, when there was a tumor identified as squamous cell carcinoma or undifferentiated carcinoma, survival was significantly

Decade

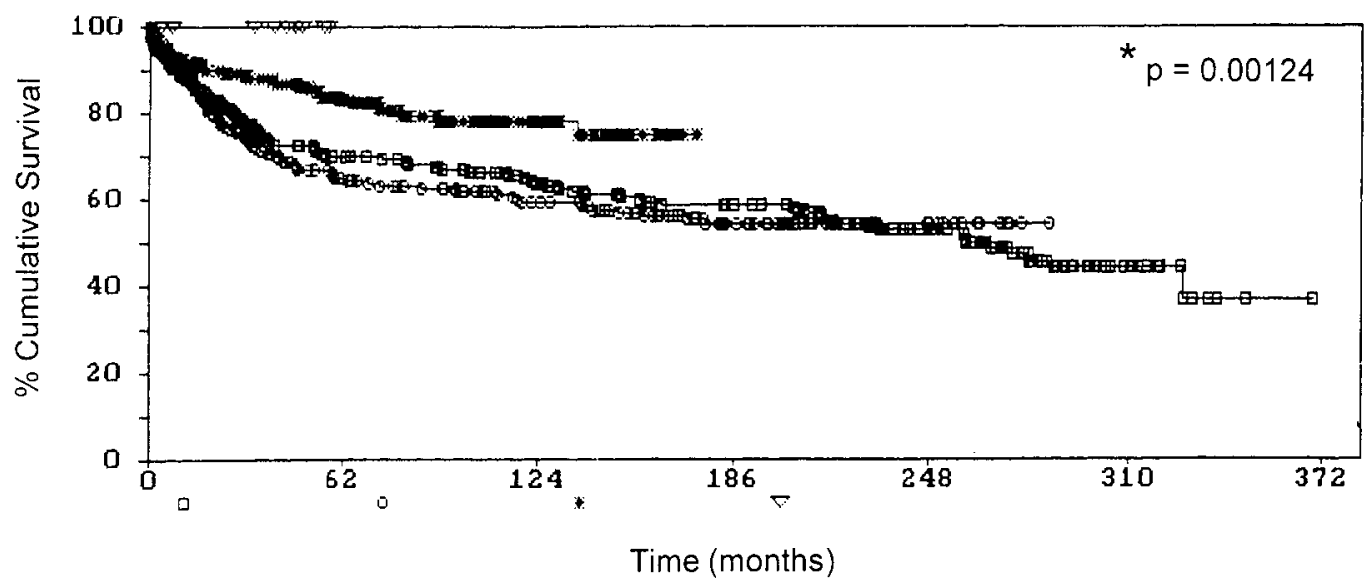

Figure 1. Overall survival after sorting according to decade of admission of patient. 


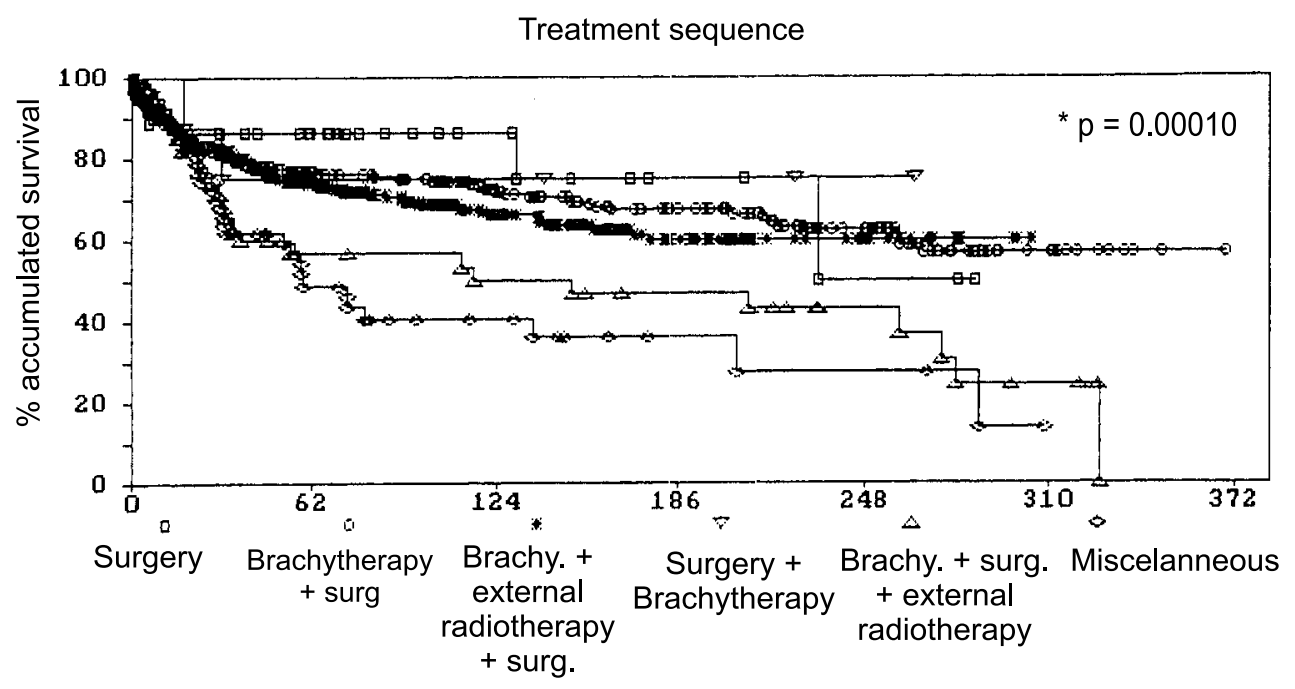

Figure 2. Overall survival after sorting according to type of treatment.

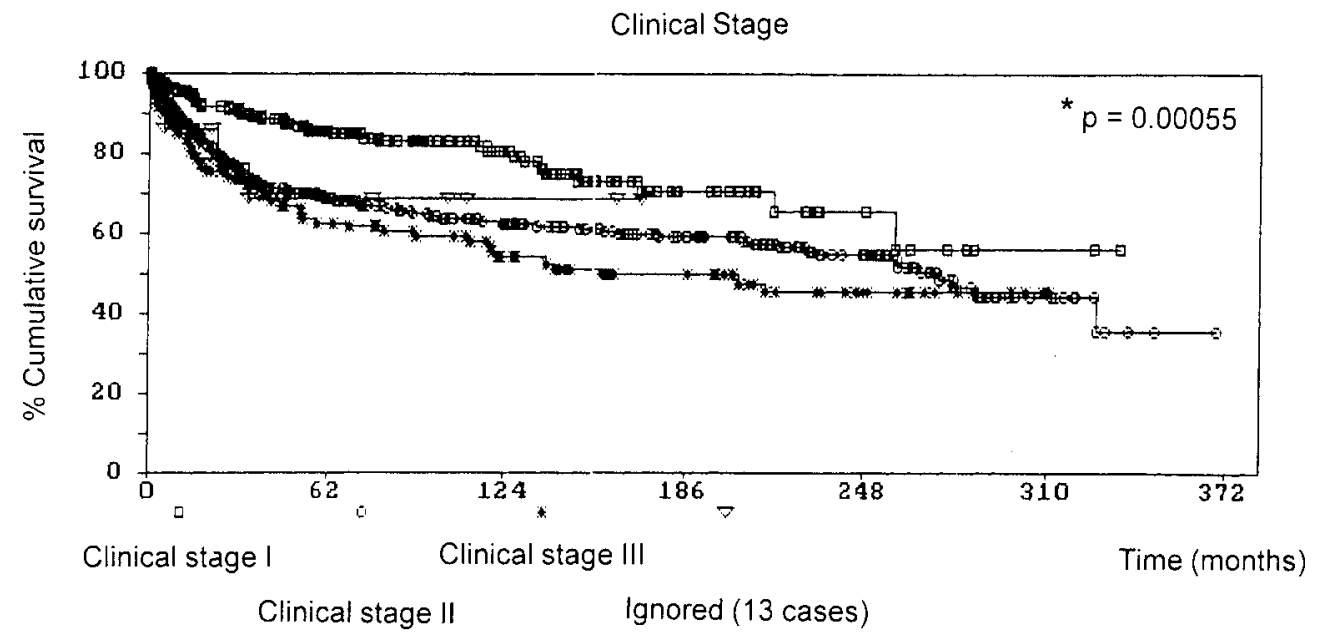

Figure 3. Overall survival correlated with clinical condition.

reduced, with no difference between the two types of tumor (Figure 5).

The set of factors of highest prognostic importance was the decade of patient admission, followed by type of treatment, residual tumor in the surgical specimen and stage of the tumor. The presence of residual tumor in the surgical specimen was more important than lymph node dissemination in terms of risk of death, in the multivariate analysis (Table 1).

The anatomopathological data relating to surgical specimens from patients were distributed as a function of clinical stage, presence or absence of a residual tumor, tumor localization and type of treatment (Table 2). Among the 32 patients $(5.2 \%)$ submitted to surgery alone, only in 7 cases $(1.1 \%$ of the total and $21.8 \%$ of the operated patients) was there no residual tumor in the product from radical surgery. Five of these patients had previously been submitted to diagnostic conic amputation. In two specific cases, the absence of residual tumor was attributed to a previous biopsy which probably involved complete removal of the preexisting tumor site, as confirmed by anatomopathological examination. All of these 7 patients were stage I and none of these 7 patients showed involvement of a locoregional lymph node (Table 2).

Among the patients submitted to preoperative irradiation, $469(74.5 \%)$ presented no residual tumor in the cervix or in the lymph nodes studied. In 133 patients $(21.1 \%)$ irradiated before surgery, there was residual disease in the cervix and or locoregional lymph nodes.

The presence of residual tumor in accordance with the clinical stage showed that 32 cases $(5.0 \%)$ were stage I, $81(12.9 \%)$ were stage II and $16(2.5 \%)$ were considered to be stage III (Table 2). In the last four cases $(0.6 \%$, excluded from the table), the clinical stage was unknown. 


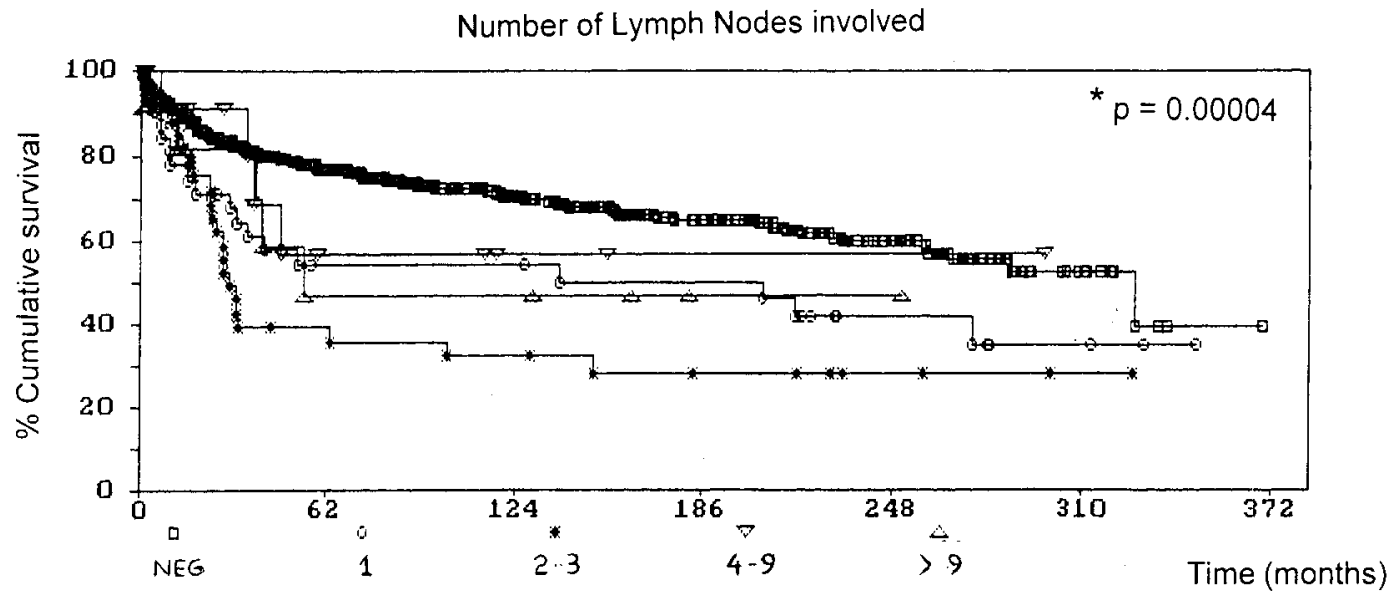

Figure 4. Overall survival correlated with the number of lymph nodes involved.

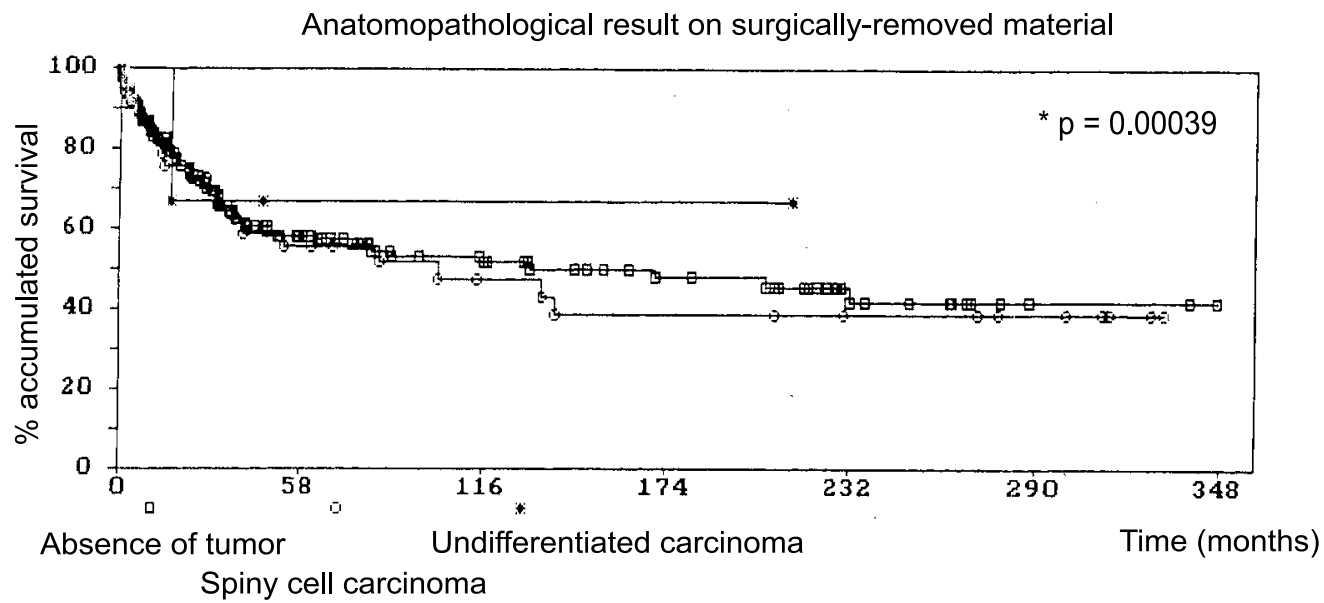

Figure 5. Overall survival correlated with the anatomopathological result from the surgical specimen.

Eight patients $(1.2 \%)$ were submitted to surgery followed by postoperative brachytherapy alone. None of them had residual tumors after radical surgery, $\mathrm{P}(-)$ and $\mathrm{N}(-)$ (Table 4). However, since these were stage II tumors, complementary brachytherapy was specifically indicated. No other information was detected in the medical records of the patients related to other prognostic factors that might further justify this complementary postoperative therapeutic indication.

\section{DISCUSSION}

Boyce et al. ${ }^{(15)}$ were among the first to emphasize the analysis of prognostic factors as a fundamental objective in the identification of patient subgroups with better or worse clinical course. ${ }^{(15)}$ These authors also pointed out that the diverse results reported in various publications cannot be fully attributed to the treatment performed, unless a judicious evaluation of all the factors involved is available.

Univariate and multivariate analysis of the results observed here through the various decades studied showed better results for the patients treated since 1970 compared to those treated in the decades of the 1950's and 1960's.

Many studies based on multivariate analysis agree in relating clinical stage to patient survival, so that adjustment of the variables as a function of the various clinical stages involved is obligatory. ${ }^{(5,15,16,17,18)}$ Although the clinical stage of carcinoma of the cervix is significantly related to patient survival, appropriately adjusted variables still need further clarification.

Tumor volume and its implications should also be carefully evaluated. Since, with few exceptions, clinical 
Table 1

Factors of highest prognostic value in the determination of the risk of death, by multivariate analysis. The results were obtained using Cox's regression method ${ }^{13}$.

\begin{tabular}{|c|c|c|c|c|}
\hline Variable & Category & $\begin{array}{c}\text { Relative } \\
\text { Risk of } \\
\text { Death } \mathbf{P}^{(\mathbf{b})}\end{array}$ & $\begin{array}{l}\text { 95\% Confidence } \\
\text { Interval }\end{array}$ & $P$ value \\
\hline Decade of & 50 & 1.0 & (Ref.) & 0.0001 \\
\hline \multirow[t]{2}{*}{ Admission } & 60 & 1.0 & $(0.8-1.4)$ & \\
\hline & $70 / 80$ & 0.5 & $(0.3-0.7)$ & \\
\hline \multirow[t]{9}{*}{ Treatment } & Surgery & 1.0 & (Ref.) & 0.0005 \\
\hline & Brachytherapy + Surgery & 1.0 & $(0.5-2.1)$ & \\
\hline & Brachytherapy + & & & \\
\hline & External Radiotherapy & & & \\
\hline & + Surgery & 1.3 & $(0.6-2.7)$ & \\
\hline & Surgery + Brachytherapy & 0.8 & $(0.2-3.8)$ & \\
\hline & Brachytherapy + Surgery + & & & \\
\hline & External Radiotherapy & 1.8 & $(0.8-4.0)$ & \\
\hline & Miscellaneous & 2.8 & $(1.3-6.1)$ & \\
\hline \multirow{3}{*}{$\begin{array}{l}\text { Pathology } \\
\text { of the } \\
\text { Surgical } \\
\text { Specimen }\end{array}$} & Absence of Tumor & 1.0 & (Ref.) & 0.0055 \\
\hline & Squamous Cell Carcinoma & 1.7 & $(1.3-2.4)$ & \\
\hline & Undifferentiated Carcinoma & 1.7 & $(1.0-2.8)$ & \\
\hline Clinical & Cs I & 1.0 & (Ref.) & 0.0575 \\
\hline \multirow[t]{3}{*}{ Stage } & Cs II & 1.6 & $(1.1-2.4)$ & \\
\hline & Cs III & 1.9 & $(1.1-3.0)$ & \\
\hline & Unknown & 1.1 & $(0.4-3.3)$ & \\
\hline
\end{tabular}

[a] Confidence Interval

[b] Using the likelihood ratio test between the present model and a reduced model excluding the variable.

stage is frequently associated with tumor volume, many investigators have made a point of distinguishing the two aspects, volume and clinical staging, and their impact on patient survival. ${ }^{(17,18,19)}$

In the present series, stage $\mathrm{Ia}^{1}$ and $\mathrm{Ia}^{2}$ microinvasive carcinomas, when duly confirmed by anatomopathological examination, were excluded from the sample studied. In cases in which there was insufficient information about the depth of invasion, clinical stage was considered to be $\mathrm{Ib}$ and the patient was included in the study. Of the 629 patients classified according to stage of the disease, $107(17 \%)$ were assigned to stage III and $14(2.2 \%)$ were considered to be of unknown stage. Most of the patients assigned to stage III were diagnosed during the decade of the 1950's, and only 17 of them were seen during the early sixties. In view of the fact that clinical staging of carcinoma of the cervix is clinical, the reevaluation of these cases is impaired because of a probable overestimate of locoregional tumor invasion. No tumor staged as IIIa appeared on the medical records. On this basis, we may only speculate that these patients, considered to be stage IIIb in those years, in fact belonged to stage IIb. In our statistical analysis we respected the parameters recorded at the time and maintained the staging originally recorded.

The information concerning the tumoral volume found in the anatomopathological reports of the medical records of our patients was 111 defined, precluding an adequate analysis of this important prognostic factor for carcinoma of the cervix.

In our series, the absence of residual tumor in the anatomopathological examination of the surgical specimen was significantly associated with overall five-year survival. Conversely, when the tumor persisted in the surgical 
Table 2

Patient distribution according to anatomopathological results from surgical specimen

\begin{tabular}{|c|c|c|c|c|c|c|}
\hline \multirow[t]{2}{*}{ CS } & \multirow{2}{*}{\multicolumn{2}{|c|}{$\begin{array}{c}\text { Site of } \\
\text { Residual } \\
\text { Tumor }\end{array}$}} & \multirow{2}{*}{$\begin{array}{l}\text { Alone } \\
\text { Surgery }\end{array}$} & \multirow{2}{*}{$\begin{array}{c}\text { Brachy } \\
+ \\
\text { Surgery }\end{array}$} & \multicolumn{2}{|c|}{ Radiotherapy } \\
\hline & & & & & $\begin{array}{c}\text { Branchy } \\
+ \text { External }\end{array}$ & Miscellaneous \\
\hline \multirow{6}{*}{ I } & $P(-)$ & $\mathrm{N}(-)$ & 7 & 68 & 45 & 3 \\
\hline & $\mathrm{P}(+)$ & $N(-)$ & 16 & 3 & 3 & 3 \\
\hline & $P(-)$ & $\mathrm{N}(+)$ & 0 & 3 & 1 & 1 \\
\hline & $\mathrm{P}(+)$ & $N(+)$ & 1 & 9 & $6^{*}$ & 2 \\
\hline & $\mathrm{P}(+)$ & N? & 0 & 0 & 1 & 0 \\
\hline & $P(-)$ & N? & 0 & 5 & 4 & 0 \\
\hline \multirow{6}{*}{ II } & $P(-)$ & $\mathrm{N}(-)$ & 0 & 82 & 111 & 18 \\
\hline & $\mathrm{P}(+)$ & $N(-)$ & 6 & 14 & 5 & 4 \\
\hline & $P(-)$ & $N(+)$ & 0 & 6 & 2 & 0 \\
\hline & $\mathrm{P}(+)$ & $N(+)$ & 1 & 26 & $14^{*}$ & 5 \\
\hline & $\mathrm{P}(+)$ & $N ?$ & 0 & 2 & 1 & 2 \\
\hline & $P(-)$ & N? & 0 & 14 & 11 & 2 \\
\hline \multirow{6}{*}{ III } & $P(-)$ & $\mathrm{N}(-)$ & 0 & 24 & 56 & 4 \\
\hline & $\mathrm{P}(+)$ & $N(-)$ & 1 & 4 & 0 & 3 \\
\hline & $P(-)$ & $N(+)$ & 0 & 3 & 0 & 0 \\
\hline & $\mathrm{P}(+)$ & $\mathrm{N}(+)$ & 0 & 2 & 1 & 2 \\
\hline & $\mathrm{P}(+)$ & N? & 0 & 0 & 1 & 0 \\
\hline & $P(-)$ & N? & 0 & 1 & 5 & 0 \\
\hline TOTAL & \multicolumn{2}{|c|}{614} & 32 & 266 & 267 & 49 \\
\hline
\end{tabular}

Cs = Clinical Stage

Brachy $=$ Brachytherapy

External $=$ External Radiotherapy

* $\quad$ we Included In the Table 6 patients (two cs I and four cs II) who died during the transoperative period and who therefore were not included in the survival curves (survival $=$ zero)

** we excluded from the table 14 cases with clinical stage unknown and 8 cases submitted to surgery followed by postoperative brachytherapy alone because none of them had residual tumors after radical surgery

$\mathrm{P}(-)$ absence of residual tumor In the cervix

$\mathrm{P}(+)$ presence of residual tumor in the cervix

$\mathrm{N}(-)$ absence of lymph node involvement

$\mathrm{N}(+)$ presence of lymph node involvement

$\mathrm{N}$ ? unknown lymph node situation

specimen and was identified as squamous cell or even undifferentiated carcinoma, survival was significantly reduced and the risk of death increased 1.7 times (Table 1). The group of 7 patients with no previous radiotherapy and absence of residual tumor after radical surgery may be considered to have an excellent prognosis, since all of them were submitted to diagnostic procedures before surgery (biopsy and conic amputation of the cervix) and in all cases these diagnostic procedures were sufficient to eradicate the initial tumor because of its probable small size (Table 2). The fact that the initial tumor was eradicated by biopsy and/or conic amputation does not necessarily mean full control of the disease. Other parameters assessed at the time of the initial biopsy permitted the classification of these cases as invasive carcinomas, and therefore considered to be stage I. A discussion about the division into stages $\mathrm{Ia}^{1}, \mathrm{Ia}^{2}$ and $\mathrm{Ib}$ is impaired, mainly for the patients operated upon in the 1950's and 1960's when parameters for the measurement of a microinvasive tumor were not yet well understood and discriminated in the anatomopathological results. Probably, for the five patients submitted to conic amputation of the cervix and then to radical hysterectomy, other doubts persisted at that time about the anatomopathological results detected from the diagnostic biopsies. On this basis, the policy of the Gynecology Service at that time was to overestimate doubtful results, indicating radical surgery as a therapeutic complement. 
Most of the 592 patients irradiated $(94.1 \%)$ received some form of preoperative radiotherapy. Among irradiated patients, $133(21 \%)$ presented residual disease in the cervix and/or locoregional lymph nodes.

Sweeney and Douglas ${ }^{(8)}$ reported data on the presence of residual tumor after external radiotherapy and brachytherapy. The results were $\mathrm{P}(+)$ and $\mathrm{N}(-)$ in $24 \%$ of cases, $\mathrm{P}(+)$ and $\mathrm{N}(+)$ in $11.8 \%$ and $\mathrm{P}(-)$ and $\mathrm{N}(+)$ in $4.9 \%$. Overall five-year survival in that study was $82.1 \%$ for stage I and $66.7 \%$ for stage II. In patients with positive lymph nodes, survival was only $35.2 \% .^{\left({ }^{8}\right)}$ According to Decker et al., ${ }^{(7)}$ the presence of residual tumor after radiotherapy, associated with the presence of positive lymph nodes, was a fatal event even though the group was small. ${ }^{(7)}$

The correlation of clinical stage with a greater possibility of residual tumor persistence was studied by Parker et al. ${ }^{(20)}$ Among their patients, those in stage I presented metastatic lymph node disease in $8 \%$ of cases, whereas those in stage II presented metastatic lymph node disease in $28 \%$ of cases. Among the patients submitted to complete preoperative radiotherapy (external radiotherapy and brachytherapy), the incidence of residual disease was $25 \%$ and the persistence of positive lymph nodes was $16 \%$. When only external radiotherapy was performed, residual tumors were found in $49 \%$ of patients and the involvement of persistent lymph nodes were found in $22 \%$ of patients. When brachytherapy alone was performed, residual tumors were found in $24 \%$ of cases and lymph nodes continued to be contaminated in $16 \%$ of patients. ${ }^{(20)}$ Only Calais et al. ${ }^{(21)}$ did not detect a prognostic value for the presence or absence of residual tumor in the previously irradiated cervix.

In our series, the largest group with persistence of residual disease (cervix and locoregional lymph nodes) was found among patients submitted to brachytherapy alone (Table 2). Finally, a group of 16 women $(2.5 \%)$ was found whose results showed residual tumor only in the lymph nodes (P (-) and $\mathrm{N}(+)$ (Table 2).

Different combinations of radiotherapy and surgery have been used in the treatment of carcinoma of the cervix, especially for stage $\mathrm{Ib} .^{(8,22,23)}$ However, these studies were not properly designed, showing problems in terms of patient selection and operability. In a random study comparing the results of radiotherapy followed by radical surgery with those of exclusive radiotherapy as treatment of stage $\mathrm{Ib}$ and IIa carcinoma of the cervix, Perez et al. ${ }^{(24)}$ did not detect a significant differences between the two treatment modalities.

With respect to surgical indication as a function of patient stage, in our sample there were 322 patients $(51 \%)$ assigned to stage II. For many of these patients, the medical records did not make a distinction between stages IIa and IIb. This type of information started to be recorded in 1965.
In view of the fact that it has always been a policy of the Hospital A.C. Camargo to combine radiotherapy with surgery for the treatment of stage IIb carcinoma of the cervix, we decided to consider this whole group of patients to be stage II. Obviously some patients in this group had a worse prognosis as a function of their tumor volume, which was usually larger among stage IIb patients. The high proportion of stage II cases in our series $(51 \%)$ also explains in part the ample indication of radiotherapy either pre- or postoperatively (Table 2).

In our study, when the variables existing in this category were analyzed as a whole, the subgroup of patients submitted to surgery alone showed better overall survival than patients treated with combined pre- or postoperative radiotherapy (Figure 2). These results are explained in part by the probably more favorable clinical stage and the absence of lymph node disease, since of the 32 patients submitted to surgery alone, 24 were in stage I and only 2 of the 32 women studied had a metastatic lymph node (Table 2). Multivariate analysis showed that this patient group was at the lowest risk of death (Table 1). When the groups for whom radiotherapy was indicated were compared, there was no difference in survival between: preoperative brachytherapy, versus preoperative brachytherapy combined with external preoperative radiotherapy, versus postoperative brachytherapy (Figure 2). The group considered to be miscellaneous presented the poorest overall survival and a 2.8 times greater risk of death (Table 1). The reason for the worse results obtained with the miscellaneous group is a matter for speculation since several confusing variables were found in these patients, impairing evaluation of the results. Fortunately, this was a small group of only 54 women. However, it should be pointed out that 25 of these patients presented some type of residual tumor in the surgical specimen. In these cases, different forms of radiotherapy were offered to the subgroup in a non-standardized and random manner, often without an appropriate justification for its indication in the medical records. This subgroup also included patients submitted to late antineoplastic chemotherapy, with no change in survival.

According to some authors, the control of the lymph node situation is a much more serious problem than the persistence and/or recurrence of central disease ${ }^{(25)}$ in the treatment of patients with carcinoma of the cervix.

The mean positivity rates for lymph nodes in stage $\mathrm{Ib}$ are variable, ranging from $4.3 \%$ to $34.2 \%{ }^{(26)}$ In this same study, the five-year survival of patients found to have positive lymph nodes ranged from $38 \%$ to $61 \%$. ${ }^{(26)}$ However, these variations in mean survival rates depend on other prognostic factors such as tumor size and extent of lymph node dissection. Surgery alone can cure patients 
with metastatic locoregional disease in a large percentage of cases. ${ }^{(2,27,28)}$ On the other hand, some studies have shown that radiotherapy can also be effective for the sterilization of metastatic lymph nodes. ${ }^{(29,30,31)}$ Many of these retrospective studies suggest that patients submitted to radiotherapy before surgery had a lower percentage of lymph nodes involved compared to those submitted to surgery alone, without previous radiotherapy. In view of the wide variation in the mean number of lymph nodes obtained by lymphadenectomy from patients, whether previously irradiated or not, it is quite difficult to judge the effects of ionizing radiation on metastatic lymph nodes.

Comparison of the results of radiotherapy with those obtained from the historical surgical series is also difficult because the situation of the lymph nodes of the patients before preoperative radiotherapy is unknown. While there is evidence that radiotherapy can sterilize metastatic lymph nodes at any stage of the disease, there is no information indicating the quantity of metastatic lymph nodes before the radiotherapeutic procedure. In summary, data in the literature indicate that radiotherapy can sterilize a considerable number of metastatic lymph nodes but not all of them, and also not in all patients.

Specifically with respect to the radicality of the surgery, the level of parametrectomy to be performed is still a matter of debate, especially in certain selected cases in early reproductive years with better prognosis and/or submitted to previous radiotherapy. ${ }^{(32,33)}$

Despite the new surgical techniques that have been developed in an attempt to quantify and reduce the radicality of the surgery, in most cases the changes proposed are limited to the level of parametrium, vagina and vesico-uterine ligament resection. ${ }^{(9)}$ Regarding lymph node resection, we did not detect any changes in the literature that would modify the classic parameters originally described. ${ }^{(2,3)}$

\section{CONCLUSION}

In whatever manner, the cases with residual disease after radiotherapy in our series have drawn attention to a subgroup of patients for whom radical surgery was necessary not only for the control of local disease (cervix) but also for the control of locoregional disease (pelvic lymph nodes).

Multivariate analysis of our sample was of prognostic value for the determination of the risk of death, which was higher for those patients with the presence of a residual tumor in the cervix after radiotherapy, compared to the groups with metastatic lymph nodes (Table 1). This result does not reduce the importance of locoregional lymph node metastases. On the contrary, it strengthens even more the need to perform pelvic lymphadenectomy since, if this had not been properly performed in our series, its prognostic value would probably have been higher, possibly supplanting other variables studied here.

\section{RESUMO}

Objetivo: Investigar o papel da persistência do tumor em pacientes submetidos a radioterapia e histerectomia radial. Tipo de estudo: Estudo retrospectivo de fatores prognósticos. Local: Hospital A.C. Camargo da Fundação Antônio Prudente, São Paulo, Brasil. Participantes: Um total de 629 casos de carcinoma espinocelular do colo do útero foram estudados, entre 1953 e 1982. Procedimentos: As pacientes foram submetidas à cirurgia radical e radioterapia, separadamente ou em combinação. Variáveis estudados: Análise Multivariada das diferentes variáveis envolvidas foi realizada de acordo com o método regressivo de Cox. Resultados: As variáveis de valor prognóstico foram, em ordem de importância: a década de admissão das pacientes, a modalidade de terapêutica empregada, a presença de tumor residual na peça operatória e o estado clínico da doença. A década de admissão foi de valor prognóstico significante. A presença de doença residual na peça operatória foi mais importante do que o envolvimento linfonodal, embora a sobrevida geral das pacientes tenha sido afetada pelo aumento no número de linfonodos comprometidos. Conclusão: $O$ tratamento radioterápico esteriliza um considerável número de linfonodos, mas não todos e em todas as pacientes. Existe um específico grupo de pacientes cuja cirurgia radical é necessária para um completo controle da doença. 


\section{REFERENCES}

1. Kottmeier HL. Surgical and radiation treatment of carcinoma of the uterine cervix. Acta Obstet Gynecol Scand Suppl 1964;43:1-48.

2. Meigs JV. Carcinoma of the cervix: the Wertheim operation. Surg Gynecol Obstet 1944;78:195-9.

3. Taussig FJ. Iliac lymphadenectomy for group II cancer of the cervix. Am J Obstet Gynecol 1943;45:733-48.

4. Wertheim E. The extended abdominal operation for carcinoma uteri. Am J Obstet Gynecol 1912;66:167-232.

5. O'Brien DM, Carmichael JA. Presurgical prognostic factors in carcinoma of the cervix, stages Ib and IIa. Am J Obstet Gynecol 1988;158:250-4.

6. Fuller AF, Elliott N, Kosloff C, Lewis Jr JL. Lymph node metastases from carcinoma of the cervix, stages Ib and IIa: implications for prognosis and treatment. Gynecol Oncol 1982;13:165-74.

7. Decker DG, Aaro LA, Hunt AB, et al. Sequential radiation and operation in carcinoma of the uterine cervix. Am J Obstet Gynecol 1965;92:35-43.

8. Sweeney WJ, Douglas RG. Treatment of carcinoma of the cervix with combined radiation and extensive surgery. Am J Obstet Gynecol 1962;84:981-91.

9. Piver MS, Rutledge F, Smith JP. Five classes of extended hysterectomy for women with cervical cancer. Obstet Gynecol 1974;44:265-72.

10. Novaes PERS. Princípios gerais da radioterapia. In: Abrão FS, editor. Tratado de Oncologia Genital e Mamária. São Paulo: Roca; 1990:141-54.

11. Kaplan EL, Meier P. Non-parametric estimation from incomplete observations. J Am Stat Assoc 1958;53:457-81.

12. Mantel N. Evaluation of survival data and two new rank order statistics arising in its consideration. Cancer Chemother Rep 966;50:163-70.

13. Cox DR: Regression models and life-tables. J R Stat Soc Br 1972;34:187-220.

14. Campos-Filho N, Franco EL. Microcomputer-assisted univariate survival data analysis using Kaplan-Meier life table estimators. Comp Meth Prog Biomed 1988;27:223-8.

15. Boyce JG, Fruchter RG, Nicastri AD, et al. Vascular invasion in stage I carcinoma of the cervix. Cancer 1984;53:1175-80.

16. Alvarez RD, Soong S, Kinney WK, et al. Identification of prognostic factors and risk groups in patients found to have nodal metastasis at the time of radical hysterectomy for early-stage squamous carcinoma of the cervix. Gynecol Oncol 1989;35:130-5.

17. Burghardt E, Baltzer J,Tulusan AH, Haas J. Results of surgical treatment of 1028 cervical cancers studied with volumetry. Cancer 1992;70:648-55.

18. Perez CA, Grigsby PW, Nene SM, et al. Effect of tumor size on the prognosis of carcinoma of the uterine cervix treated with irradiation alone. Cancer 1992;69:2796-806.
19. Piver MS, Chung WS. Prognostic significance of cervical lesion size and pelvic node metastases in cervical carcinoma. Obstet Gynecol 1975;46:507-10.

20. Parker RT, Wilbanks GD, Yowell RK, Carter FB. Radical hysterectomy and pelvic lymphadenectomy with and without preoperative radiotherapy for cervical cancer. Am J Obstet Gynecol 1967;99:933-43.

21. Calais G, Floch OL, Chauvet B, et al. Carcinoma of the uterine cervix stage Ib and early stage II: prognostic value of the histological tumor regression after initial brachytherapy. Int $\mathrm{J}$ Radiat Oncol Biol Phys 1989;17:1231-5.

22. Einhorn N, Patek E, Sjoberg B. Outcome of different treatment modalities in cervix carcinoma stage Ib and IIa. Cancer 1985;55:949-55.

23. Perez CA, Breaux S, Askin F, et al. Irradiation alone or in combination with surgery in stage Ib and IIa carcinoma of the uterine cervix: a non-randomized comparison. Cancer 1979;43:1062-72.

24. Perez CA, Camel HM, Kao MS, Hederman MA. Randomized study of preoperative radiation and surgery or irradiation alone in the treatment of stage Ib and IIa carcinoma of the uterine cervix: final report. Gynecol Oncol 1987;27:129-40.

25. Rubin SC, Hoskins WJ, Lewis Jr JL. Radical hysterectomy for recurrent cervical cancer following radiation therapy. Gynecol Oncol 1987;27:316-22.

26. Delgado G. Stage Ib squamous cancer of the cervix: the choice of treatment. Obstet Gynecol Surv 1978;33:174-83.

27. Brunschwig A. Surgical treatment of stage I cancer of the cervix. Cancer 1960;13:34-6.

28. Underwood PB, Wilson WC, Kreutner A, et al. Radical hysterectomy: a critical review of twenty-two years' experience. Am J Obstet Gynecol 1979;134:889-98.

29. Burch JC, Chalfant RL. Preoperative radium irradiation and radical hysterectomy in the treatment of cancer of the cervix. Am J Obstet Gynecol 1970;106:1054-64.

30. Lagasse LD, Smith ML, Moore JG, et al. The effect of radiation therapy on pelvic lymph node involvement in stage I carcinoma of the cervix. Am J Obstet Gynecol 1974;119:328-34.

31. Rutledge FN, Fletcher GH, Macdonald EJ. Pelvic lymphadenectomy as an adjuvant to radiation therapy in treatment for cancer of the cervix. AJR Am J Roentgenol Rad Ther 1965;93:607-14.

32. DiSaia PJ, Townsend DE, Morrow CP. The rationale for less than radical treatment for gynecologic malignancy in early reproductive years. Obstet Gynecol Surv 1974;29:581-93.

33. Rutledge FN, Wharton JT, Fletcher GH. Clinical studies with adjunctive surgery and irradiation therapy in the treatment of carcinoma of the cervix. Cancer 1976;36:596-602. 